\title{
Sistema de Avaliação do Relacionamento Parental (SARP)
}

O recente lançamento do Sistema de Avaliação do Relacionamento Parental (SARP) pode ser considerado um avanço significativo para a avaliação psicológica no Brasil, especialmente no que tange o contexto forense. Ele foi desenvolvido pelas psicólogas Dra. Vivian de Medeiros Lago e Dra. Denise Ruschel Bandeira, do Grupo de Estudo, Aplicação e Pesquisa em Avaliação Psicológica (GEAPAP) da Universidade Federal do Rio Grande do Sul (UFRGS) e publicado pela Casa do Psicólogo (Pearson) em 2013. O SARP foi construído com o objetivo de auxiliar psicólogos e assistentes sociais na avaliação da qualidade do relacionamento entre crianças e seus responsáveis, considerando situações de disputa de guarda e regulamentação de visitas em casos de perícias judiciais. Fundamentado nos pressupostos da Teoria Familiar Estrutural, a definição de relacionamento parental adotada no SARP é entendida como "a capacidade dos genitores de atender às necessidades de afeto, cuidados, proteção, educação, lazer e segurança dos filhos" (Lago \& Bandeira, 2013, p. 20).

Quando os responsáveis não conseguem chegar a um acordo com relação aos cuidados com os filhos após a ruptura do vínculo conjugal, torna-se necessária a intervenção judicial (Rovinski, 2007). Assim, eles são avaliados a fim de investigar quem é o mais indicado para ter a guarda legal da criança (Brasil, 2004). As avaliações objetivam descrever a qualidade do relacionamento parental (Lago \& Bandeira, 2008), através da compatibilidade entre as competências parentais e as necessidades da criança (Rivera, Martínez, Fernandez, \& Pérez, 2002).

A competência parental está diretamente relacionada à capacidade dos pais para garantirem o bem-estar dos filhos. Para avaliá-la, investigam-se as potencialidades dos responsáveis para atenderem as necessidades das crianças (Rovinski, 2007). Como necessidades das crianças, inclui-se o atendimento das áreas físico-biológica, cognitiva, emocional e social. A área das necessidades físico-biológicas diz respeito aos cuidados com integridade física, alimentação, higiene, sono, atividade física e proteção frente a riscos reais. As cognitivas englobam a estimulação sensorial, a exploração e compreensão da realidade física e social e a aquisição de um sistema de normas e valores. As necessidades emocionais e sociais compreendem segurança emocional, identidade pessoal e autoestima, rede de relações sociais, estabelecimento de limites de comportamento e educação (Rivera et al., 2002).

Diante da relevância das relações parentais no desenvolvimento humano, as autoras do SARP, em estudo anterior, concluíram que a qualidade dos vínculos entre pais/responsáveis e filhos exerce uma importante influência no bem-estar psicológico das crianças (Lago, Amaral, Bosa, \& Bandeira, 2010). Nesse estudo, elas observaram ainda uma carência de técnicas ou instrumentos desenvolvidos para o contexto forense que auxiliem os profissionais nessa investigação (especialmente no Brasil). Sugeriram, dessa forma, a realização de estudos de adaptação ou de construção de instrumentos brasileiros que visassem à avaliação da relação entre pais/responsáveis e filhos (Lago et al., 2010).

A partir de tal constatação, a Dra. Vivian de Medeiros Lago, em sua tese de doutorado intitulada "Construção de um Sistema de Avaliação do Relacionamento Parental para Situações de Disputa de Guarda" (Lago, 2012), com orientação da Dra. Denise Ruschel Bandeira, deu origem ao SARP. Salienta-se que a sua tese foi vencedora do "Prêmio Capes de Tese" em 2013 na área de Psicologia.

O SARP é composto de três técnicas aplicadas a responsáveis e filhos: a entrevista SARP, o protocolo de avaliação infantil "Meu Amigo de Papel" (uma versão para meninos e uma para meninas) e a Escala SARP. Ainda há um livreto de apresentação do profissional, para ser utilizado juntamente com o "Meu Amigo de Papel".

A entrevista SARP é composta por 32 questões, divididas em oito áreas: rotina da criança, escola e amigos, comunicação, rede de apoio, estabelecimento de regras, comunicação e flexibilidade com o ex-cônjuge, ajustes pós-separação e motivação para ficar com a guarda. A proposta é que a entrevista seja feita individualmente com cada um dos responsáveis envolvidos na disputa de guarda.

O protocolo "Meu Amigo de Papel" é um material gráfico com imagens e espaços para a criança preencher, e pode ser aplicado em crianças de 5 a 12 anos. O material, inspirado no material britânico My needs, wishes and feelings Pack, livreto distribuído gratuitamente na instituição Children and Family Court Advisory and Support Service (CAFCASS), oportuniza que a criança possa participar do processo de disputa de guarda, emitindo 
sua opinião e seus desejos. Além disso, ela é informada, com uma linguagem pertinente à sua idade, sobre o que está acontecendo, esclarecendo-lhe que a responsabilidade pela tomada de decisão não é sua. A escuta qualificada por parte do profissional, nesse sentido, possibilita a confrontação dos resultados obtidos pelos pais e pelos filhos, visando à checagem da veracidade das informações (Lago et al., 2010).

A Escala SARP é a última etapa do trabalho. O objetivo é que a escala seja pontuada pelo próprio examinador, visto que, para preenchê-la, o profissional pode ter em mente não somente as informações fornecidas pelos responsáveis na entrevista, mas também os dados oriundos do protocolo "Meu Amigo de Papel", das observações clínicas, de outros testes ou de entrevistas com terceiros. Ela é dividida em dois eixos principais: competências parentais, composto de cinco dimensões, e necessidades dos filhos, dividido em três. As cinco dimensões do eixo competências parentais são: relação interparental, características afetivoemocionais, cuidados básicos, proteção frente a riscos reais e sistema de normas e valores. Já as três dimensões do eixo necessidades dos filhos são: segurança emocional, desenvolvimento de identidade e educação e lazer. Todas as dimensões são ainda divididas em itens, chegando ao total de 26 , e cada um deles é pontuado com relação à adequação ou prejuízo referente ao relacionamento parental.

O resultado final do SARP aponta quais atributos do relacionamento parental estão bem atendidos e quais estão deficitários, a partir de uma média dos itens pontuados em cada dimensão (quanto mais próximo de um, mais prejudicado). É possível comparar as médias dessas pontuações obtidas pelos responsáveis por meio da visualização dos escores no gráfico que é gerado com a transposição de tais resultados. O escore total, no entanto, não é passível de interpretações, visto que o manual orienta que não se deve considerar necessariamente o responsável com maior pontuação como aquele que deverá ficar com a guarda da criança. É fundamental uma compreensão dinâmica do caso para subsidiar recomendações acerca da disputa.

Apesar de ter sido desenvolvido pensando-se no contexto forense e na disputa de guarda e regulamentação de visitas, o SARP pode ser utilizado, com devidas adaptações, em outras realidades de avaliação em que se deseja investigar a relação parental, como em contextos de adoção, por exemplo. Tais adaptações incluem a forma de utilização da entrevista SARP e do "Meu Amigo de Papel". De acordo com o manual, o profissional fica livre para adicionar ou suprimir questões, as quais estejam ou não de acordo com o caso com o qual se está trabalhando.

Para profissionais com experiência em entrevista, o roteiro proposto pelas autoras pode tornar-se extenso e, em alguns pontos, até cansativo, uma vez que abrange todas as fases do desenvolvimento da criança e as questões relacionadas ao relacionamento conjugal e parental. No entanto, fica a critério do profissional suprimir questões da entrevista ou atividades do protocolo infantil que julgar fora de contexto para a situação de avaliação na qual se está trabalhando. Também é possível adaptá-lo às condições de tempo disponível para a avaliação, bem como à relevância para o caso em questão, independentemente do contexto utilizado.

De forma sistemática ao longo do manual, as autoras enfatizam a necessidade de treinamento do profissional que pretende utilizar o método. Apesar do guia instrumentalizar os profissionais para a correta aplicação do SARP, é vista como fundamental a familiaridade com o contexto forense e treinamento em entrevistas, bem como o conhecimento sobre desenvolvimento infantil e relacionamento parental. Dessa forma, especialmente por não se restringir ao uso do psicólogo (também é indicado para psiquiatras e assistentes sociais), entende-se como fundamental a capacitação dos profissionais antes da utilização do SARP por meio de treinamento para aplicação do instrumento.

Os estudos de validade e fidedignidade da escala SARP têm indicado adequadas propriedades psicométricas. O teste da fidedignidade entre juízes (duas psicólogas e uma assistente social devidamente treinadas) indicou que o sistema de pontuação da escala SARP apresenta adequada consistência entre avaliadores (Lago \& Bandeira, 2013). Um estudo de validade clínica do SARP, avaliando três famílias com o SARP, o Inventário de Estilos Parentais (IEP; Gomide, 2006) e o Teste de Apercepção Familiar (FAT; Sotile, Julian, Henry, \& Sotile, 1991), verificou a congruência interna, externa e teórica do SARP com essas outras medidas (Lago \& Bandeira, 2013).

O manual do SARP traz ainda a apresentação de três casos em diferentes contextos: família constituída, família divorciada e perícia de disputa de guarda. Em todos eles, as autoras ilustram a aplicação do SARP, descrevendo os dados obtidos a partir das três técnicas que compõem o instrumento (Entrevista SARP, protocolo "Meu Amigo de Papel" e Escala SARP).

Diante do exposto, conclui-se que o diferencial do SARP é a sua flexibilidade, uma vez que o preenchimento 
da escala depende da interpretação do aplicador e da sua visão sobre a avaliação de forma geral, incluindo outras técnicas e instrumentos. Assim, o método objetiva ser mais uma ferramenta para os profissionais que necessitam avaliar o relacionamento parental, e o resultado da escala não pretende definir quem dos familiares ficará com a guarda. Dessa forma, para fins desta nota técnica, entende-se que, em caso de disputa de guarda entre genitores, por exemplo, se a mãe pontuar mais que o pai na escala, isso não significa que, necessariamente, ela será indicada como a pessoa com mais condições de exercer a parentalidade. Pode-se, nesse caso, optar por sugerir a guarda compartilhada, a partir do entendimento do profissional acerca da situação que melhor atenda às necessidades da criança.

Avalia-se como fundamental a continuidade das pesquisas na área de avaliação do relacionamento parental, com a utilização e adaptação do SARP em outros contextos. Considera-se importante que grupos de pesquisa que trabalham com avaliação psicológica (incluindo o GEAPAP, grupo das autoras) invistam em pesquisas sobre o SARP, a fim de sugerir aprimoramentos do instrumento para uma melhor utilização e aproveitamento dele.

\section{Referências}

Brasil (2004). Constituição Federal, Código Civil, Código de Processo Civil. 6. ed. São Paulo: Revista dos Tribunais.

Gomide, P. I. C. (2006). Inventário de Estilos Parentais. Petrópolis, RJ: Vozes.
Lago, V. M. (2012). Construção de um sistema de avaliação do relacionamento parental para situações de disputa de guarda (Tese de doutoramento). Universidade Federal do Rio Grande do Sul, Porto Alegre, RS.

Lago, V. M., Amaral, C. E. S., Bosa, C. A., \& Bandeira, D. R. (2010). Instrumentos que avaliam a relação entre pais e filhos. Revista Brasileira de Crescimento e Desenvolvimento Humano, 20, 330-341. Recuperado de http://pepsic.bvsalud.org/pdf/ rbcdh/v20n2/15.pdf

Lago, V. M., \& Bandeira, D. R. (2008). As práticas em avaliação psicológica envolvendo disputa de guarda no Brasil. Avaliação Psicológica, 7(2), 222-234. Recuperado de http://pepsic.bvsalud.org/pdf/ avp/v7n2/v7n2a13.pdf

Lago, V. M, \& Bandeira, D. R. (2013). Sistema de Avaliação do Relacionamento Parental - SARP, Manual. São Paulo: Casa do Psicólogo.

Rivera, F. F., Martínez, D. S., Fernández, R. A., \& Pérez, M. N. (2002). Psicología jurídica de la familia: Intervención de casos de separeción y divórcio. Barcelona: Dedecs.

Rovinski, S. L. R. (2007). Fundamentos da perícia psicológica forense. São Paulo: Vetor.

Sotile, W. M., Julian III, A., Henry, S. E., \& Sotile, M. O. (1991). Family Apperception Test: Manual. Los Angeles: Western Psychological Services.

Recebido em: 19/08/2014 Primeira reformulação em: 17/06/2015 Segunda reformulação em: 23/10/2015

Aprovado em: 27/10/2015 
Sobre as autoras:

Beatriz Cancela Cattani é psicóloga (CRP 07/20897), especialista em Avaliação Psicológica (UFRGS) e mestranda em Psicologia (UFRGS), membro do Grupo de Estudo, Aplicação e Pesquisa em Avaliação Psicológica (GEAPAP). Áreas de interesse: Avaliação Psicológica, Psicodiagnóstico, Psicanálise, Psicologia Infantil, Desenvolvimento Infantil, Infância e Adolescência.

E-mail: beatriz.cattani@gmail.com

Helena Berton Eidt é psicóloga judiciária na Vara da Infância e da Juventude da Comarca da Capital/SC (CRP 12/04689) e mestranda em Psicologia (UFRGS), membro do Grupo de Estudo, Aplicação e Pesquisa em Avaliação Psicológica (GEAPAP). Áreas de interesse: Avaliação Psicológica, Psicologia Jurídica, Infância e Juventude. E-mail: helenaberton@hotmail.com

Contato com as autoras:

Beatriz Cancela Cattani

Rua Ramiro Barcelos, 2.600/sala 120 (GEAPAP). Bairro Santa Cecília Porto Alegre - RS.

CEP: 90035-003

E-mail: beatriz.cattani@gmail.com 